\title{
Novel Compact CPW-Fed Antennas with Harmonic Suppression and Bandwidth Enhancement
}

\author{
Zhi-Li Zhou, Li Li, and Jing-Song Hong \\ Institute of Applied Physics, University of Electronic Science and Technology, Chengdu 610054, China \\ Correspondence should be addressed to Zhi-Li Zhou, zhouzhili003@163.com
}

Received 9 December 2011; Accepted 4 July 2012

Academic Editor: Hala A. Elsadek

Copyright () 2012 Zhi-Li Zhou et al. This is an open access article distributed under the Creative Commons Attribution License, which permits unrestricted use, distribution, and reproduction in any medium, provided the original work is properly cited.

Novel compact CPW-fed antennas with harmonic suppression are presented and investigated in detail. By inserting symmetrical slots connected to the end of CPW transmission line in the ground plane, and exploiting parasitic technique, harmonic suppression, compact size, as well as wide bandwidth are obtained. General performances of the proposed antennas are studied by equivalent transmission line circuits. Moreover, the steps of constructing such harmonic suppression antennas are derived. Eventually, the experiment results verified the validation of the proposed harmonic suppression antennas.

\section{Introduction}

The harmonic suppression antenna (HSA) has become very attractive due to its great advantages such as low cost, small size, and easy integration in wireless communication and microwave power transmission (MPT) systems $[1,2]$. Conventionally, a harmonic suppression filter is chosen in these systems to avoid harmonic interference and achieve good system performances. However, it is bulky, expensive, and hard to be integrated in monolithic microwave integrated (MMIC) devices. To overcome these defects, harmonic suppression technologies for antenna have been widely investigated recently [3-9]. Defected ground plane structure (DGS) and photonic band gap (PBG) structure are widely used to achieve harmonic suppression function $[10,11]$. However, most of them are focus on microstripfed antennas. Compared with the microwave-fed antennas, CPW-fed antennas exhibit even more promising merits, such as wider bandwidth, simpler structure, and easier integration with active devices and MMIC devices. It reveals us that the CPW-fed antennas with harmonic suppression will be more attractive and applicable. Nevertheless, there are only a few researches on that [12-14], and much more works is required to fulfill its potential. In [12], a CPW-fed broadband HSA $(1.56 \mathrm{GHz}-2.88 \mathrm{GHz})$ was achieved by exploiting PBG structures with cross-shaped lattices. Besides, by inserting symmetrical slots in the ground plane of an open-ended $\mathrm{CPW}$-fed transmission line, an HSA with fairly compact size $(26 \mathrm{~mm} \times 15 \mathrm{~mm})$ was obtained in [13]. However, the broadband HSA in [12] is limited by its rather big size, and the compact HSA in [13] suffered a quite narrow bandwidth.

In this paper, several novel compact CPW-fed antennas with harmonic suppression are presented. In order to suppress the harmonic frequencies, symmetrical slots connected to the end of CPW-fed transmission line are etched on the ground plane. Moreover, by employing parasitic technique, bandwidth enhancement is also achieved. General performances of the proposed antennas are investigated by equivalent transmission line circuits. Furthermore, the steps of constructing such HSAs are derived. Eventually, the experiment results verified the validation of the proposed HSAs.

\section{Antenna Geometry and Mechanism}

2.1. Simple Slot-Type HSA. A normal open-ended CPWfed transmission line, as shown in Figure 1(a), will not radiate electromagnetic energy. However, radiation behavior can be brought by creating discontinuities in the CPW-fed transmission line, and by etching slots on the ground plane. In order to excite desired resonant frequency, two simple symmetrical short-ended slots connected with the end of 


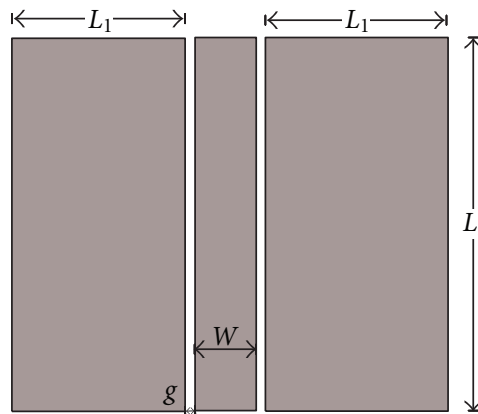

(a)

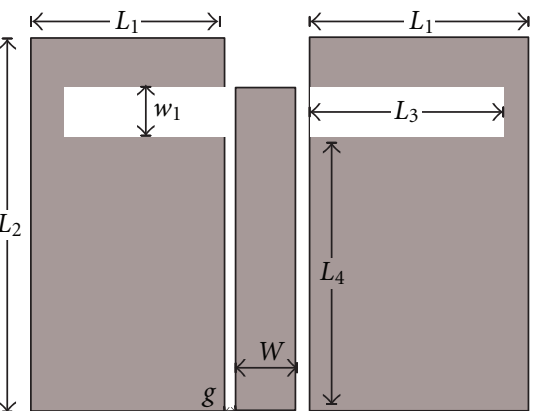

(b)

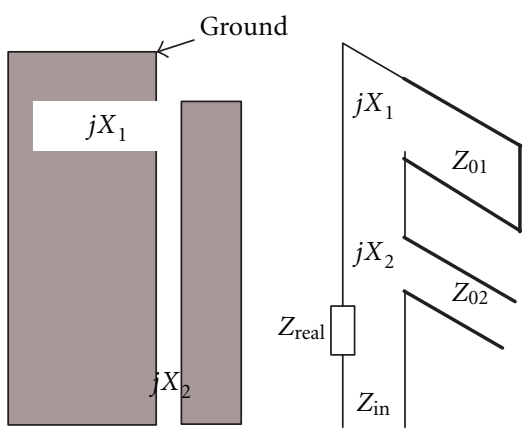

(c)

Figure 1: (a) A normal open-ended CPW-fed transmission line. (b) The geometry of antenna 1 and (c) The equivalent transmission line circuits for antenna 1 .

the CPW transmission line were etched on the ground plane, as shown in Figure 1(b), named antenna 1. The short-ended slots are the radiator and impedance controller. They can be expressed as series pure imaginary impedance load at the end of the CPW-fed transmission line, according to the equivalent transmission line circuits, as shown in Figure 1(c). The imaginary part of the input impedance for antenna $1 \mathrm{can}$ be expressed as.

$j X_{1}, j X_{2}$ are the imaginary part of the input impedances of the equivalent transmission line for the short-ended slot and the CPW feeding line, respectively,

$$
Z_{\text {imag }}=j X_{1}+j X_{2}=j Z_{01} \operatorname{tg} \beta L_{3}+j Z_{02} \operatorname{ctg} \beta L_{4},
$$

where $Z_{01}, Z_{02}$ are the characteristic impedances of the equivalent transmission line. And they depend on the width of the symmetrical slot, the height of substrate, as well as the dielectric constant of the substrate.

To achieve the desired resonant frequency, we can take (1), which is derived from the equivalent T.L. circuit model, into account in obtaining the parameters of the short-ended slots at the beginning design. And then, the full-wave solver CST has been used to finalize and optimize the structure. By changing the length of the slots, the imaginary part of the input impedance for antenna 1 can be close to null, thus pure resistive input impedance can be produced. As a result, resonant can be excited at the desired frequency.

Antenna 1 was printed on a dielectric substrate with thickness of $1.6 \mathrm{~mm}$, and relative permittivity of 4.5. Simulation and optimization were performed with the commercial
TABLE 1: Antenna dimensions.

\begin{tabular}{lcc}
\hline Antenna 1 & Antenna 2 & Antenna 3 \\
\hline$L_{1}=17.3 \mathrm{~mm}$ & $L_{1}=9.1 \mathrm{~mm}$ & $L_{1}=20 \mathrm{~mm}$ \\
$L_{2}=20 \mathrm{~mm}$ & $L_{2}=3 \mathrm{~mm}$ & $R_{1}=15 \mathrm{~mm}$ \\
$L_{3}=16.5 \mathrm{~mm}$ & $L_{3}=9 \mathrm{~mm}$ & $R_{2}=14 \mathrm{~mm}$ \\
$L_{4}=16 \mathrm{~mm}$ & $L_{4}=18 \mathrm{~mm}$ & $a_{1}=15$ degree \\
$W_{1}=2 \mathrm{~mm}$ & $W_{1}=W_{2}=2 \mathrm{~mm}$ & $a_{2}=20$ degree \\
$g=0.2 \mathrm{~mm}$ & $g=0.2 \mathrm{~mm}$ & $g=0.2 \mathrm{~mm}$ \\
$W=3 \mathrm{~mm}$ & $W=3 \mathrm{~mm}$ & $W=3 \mathrm{~mm}$ \\
\hline
\end{tabular}

software CST. And the final results, with the optimized parameters listed in Table 1, are demonstrated in Figure 2.

To obtain the harmonic suppression, additional antenna structures which act as a wide-band stop filter are usually required for microwave-fed antennas [15]. Generally, such structures are not necessary for the proposed CPW-fed HSAs since the open-ended CPW-fed transmission line can be expressed a wide-band stop filter. However, it can be seen from the results in Figure 2, the simple symmetrical slots in antenna 1 cannot suppress the third harmonic frequency effectively, though it can suppress the second harmonic frequency well. In order to excite the fundamental frequency and suppress both the second and third harmonic frequencies, further studies were carried out.

The fundamental resonant frequency is supposed to be $f_{0}$. According to what have mentioned above, the length of the symmetrical slots should be about $\lambda / 4$ ( $\lambda$ is the wavelength of the desired resonant frequency in the substrate). 


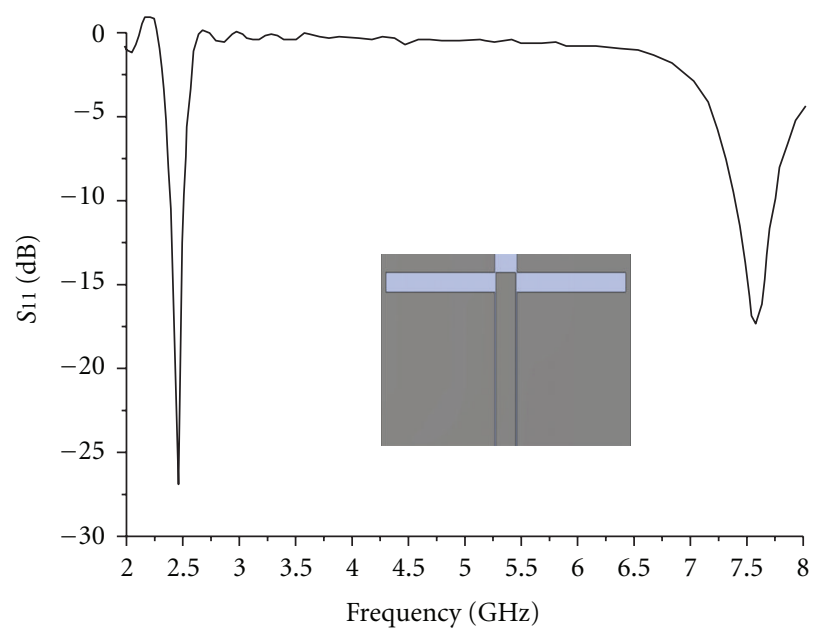

(a)

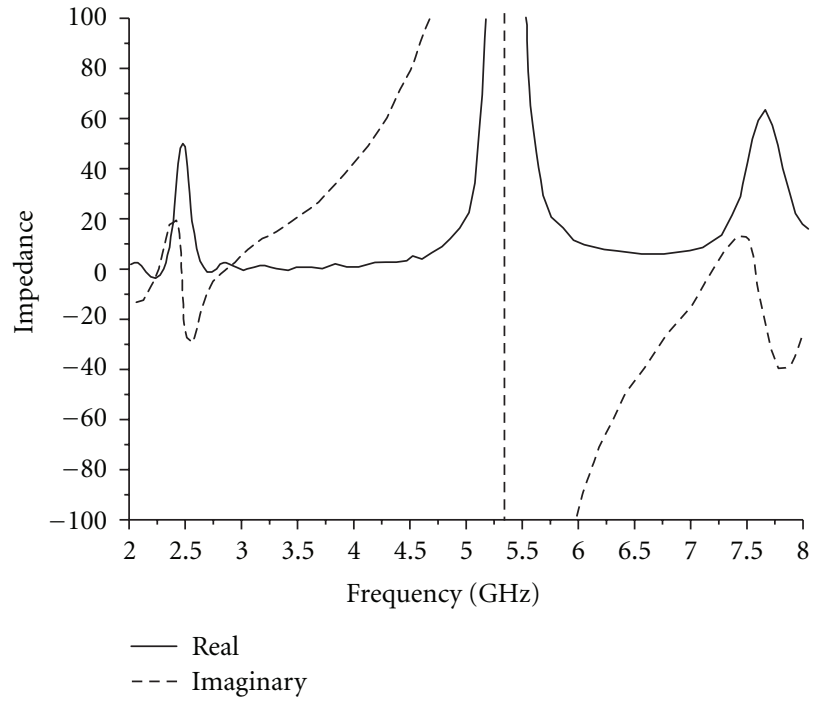

(b)

FIgURE 2: (a) The simulated return losses of antenna 1 and (b) The simulated input impedance of antenna 1.

As a result, the length of the symmetrical slots is also equal to $3 \lambda_{3 \text { th }} / 4$ ( $\lambda_{3 \text { th }}$ is the wavelength of the third harmonic frequency in the substrate). Therefore, pure resistive input impedance is also achieved at the third harmonic frequency, which means that a spurious resonant is also excited at the third harmonic frequency. Accordingly, necessary modification must be done on the basis of antenna 1 , so as to excite the fundamental resonant and suppress both the second and third harmonic frequencies. Thus, the transmission line which connected with pure reactive load is considered, as shown in Figure 3(a).

Antenna 2 is printed on a dielectric substrate with thickness of $1.6 \mathrm{~mm}$, and relative permittivity of 4.5 . Two symmetrical short-ended transmission lines were connected with the end of the symmetrical slots, respectively, as shown in Figure 3(b). The equivalent transmission line circuit of antenna 2 is also presented in Figure 3(c). According to the transmission line impedance equation, the imaginary part of the input impedance of antenna 2 is

$$
Z_{\text {imag }}=j X_{1}+j X_{2}=Z_{01} \frac{Z_{L}+j Z_{01} \operatorname{tg} \beta L_{2}}{Z_{01}+j Z_{L} \operatorname{tg} \beta L_{2}}-j Z_{02} \operatorname{ctg} \beta L_{4}
$$

where $Z_{01}, Z_{02}$ are the characteristic impedances of the equivalent transmission lines:

$$
Z_{L}=Z_{\text {stub1 }}+Z_{\text {stub2 }}=j Z_{01} \operatorname{tg} \beta L_{1}+j Z_{03} \operatorname{tg} \beta L_{3} .
$$

We can also take (2) and (3), which are derived from the equivalent T.L. circuit models, into account in obtaining the parameters of the slots at the beginning design, and then finalize and optimize the structures by the full-wave solver. Optimized parameters of the proposed antenna 2 are listed in Table 1. Figure 4 depicts the final results. limitation of antenna is probably the most serious problem in the practical applications of engineering. In order to improve the bandwidth of the proposed HSA, parasitic technique is applied, as shown in Figure 5(a). Two pairs of symmetrical slots connected with the end of the CPW-fed transmission line are etching on the ground plane. Each pair of symmetrical slots can excite a resonant mode. So, both broadband characteristic and harmonic suppression function can be obtained when the two resonant frequencies are close enough. The transmission line equivalent circuit of the proposed antenna 3 is also presented in Figure 5(b). According to the transmission line impedance equation, the imaginary part of the input impedance for antenna 3 is

$$
Z_{\text {imag }}=j X_{1}+j X_{2}+j X_{3},
$$

$j X_{1}, j X_{2}$ are the impedances of the equivalent transmission line of the two pairs of symmetrical slots connected with the CPW-fed transmission line, which can be seen as two pairs of tapered transmission line (Figure 6), respectively. $Z_{01}, Z_{02}, \ldots, Z_{0 N}$, are the characteristic impedances of the equivalent transmission lines. Considering the fact that the T.L model is used to provide only the initial estimates for the antenna designed parameters and in order to simplify the design, $N$ is chosen to be 2 in this design, that is

$$
\begin{gathered}
j X_{1}\left(j X_{2}\right)=Z_{01} \frac{j Z_{02} \operatorname{tg} \beta((R 1(R 2)) / 2)+j Z_{01} \operatorname{tg} \beta((R 1(R 2)) / 2)}{Z_{01}-Z_{02} \operatorname{tg} \beta((R 1(R 2)) / 2) \operatorname{tg} \beta((R 1(R 2)) / 2)}, \\
j X_{3}=-j Z_{03} \operatorname{ctg} \beta L_{1},
\end{gathered}
$$

$Z_{03}$ is the characteristic impedance of the equivalent CPWfed transmission line. Similarly, we can take (5) into account in obtaining the lengths of the slots at the beginning design and tune the geometry for the final design. Make sure that the pure resistive input impedance is obtained only at the 


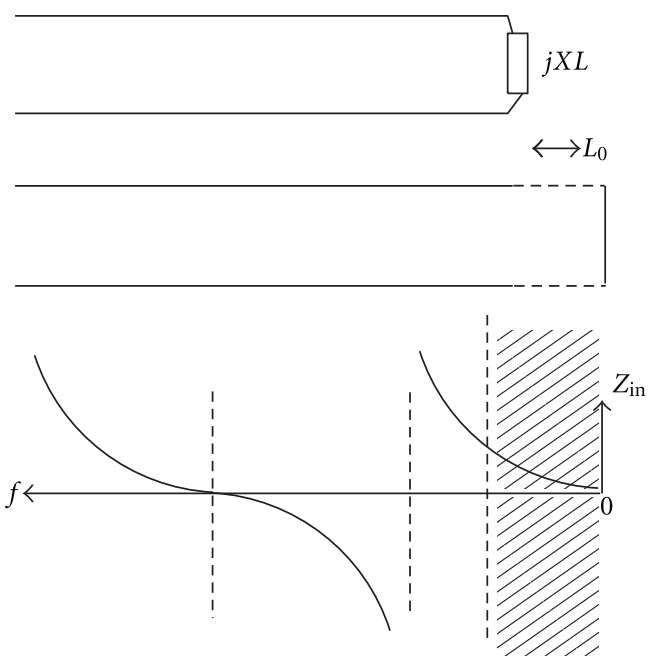

(a)
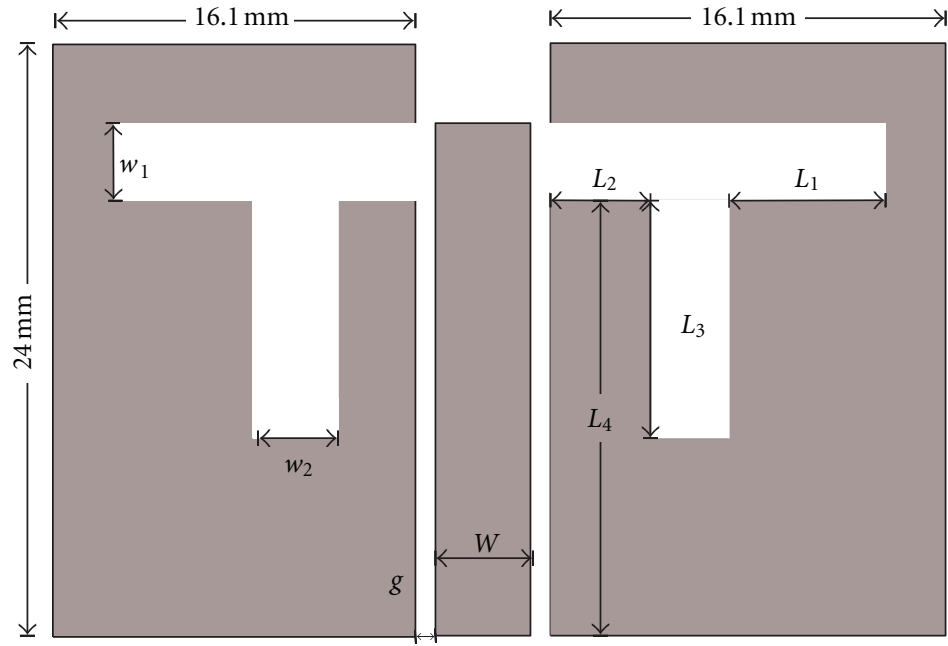

(b)

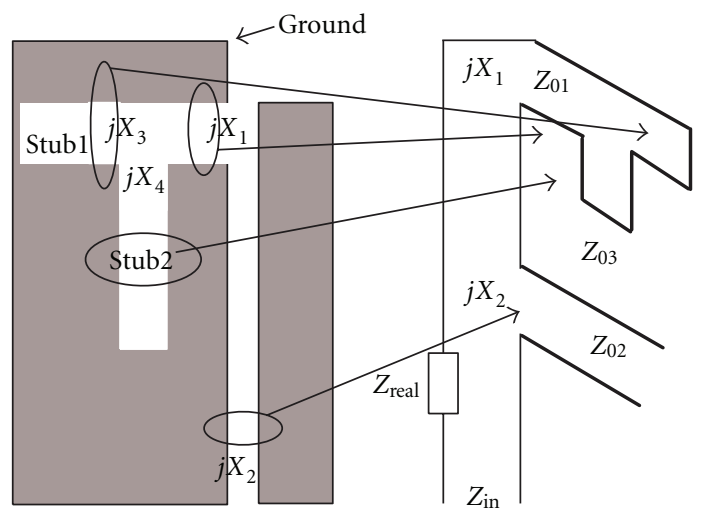

(c)

FIGURE 3: (a) The impedance of purely reactive loaded transmission line. (b) The geometry of antenna 2 and (c) The equivalent transmission line circuits for antenna 2.

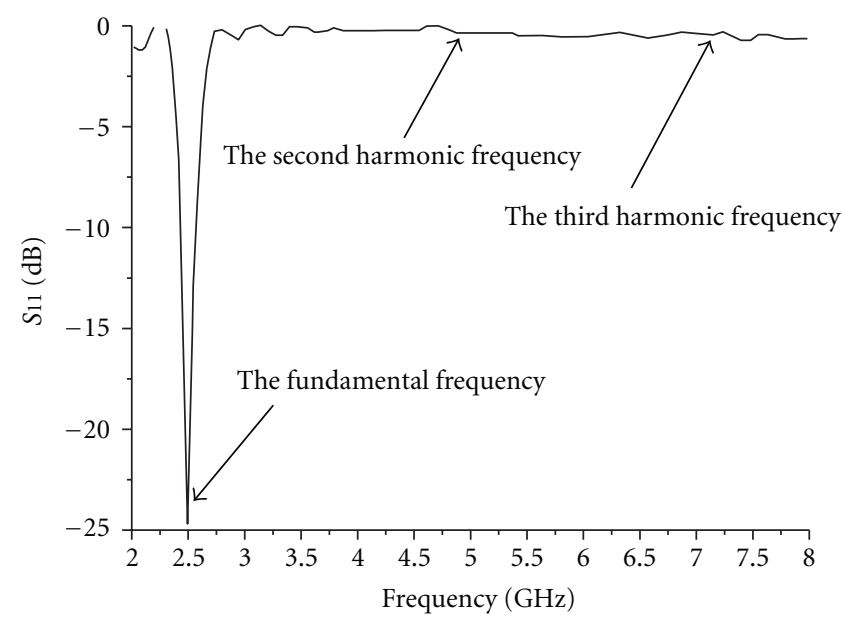

(a)

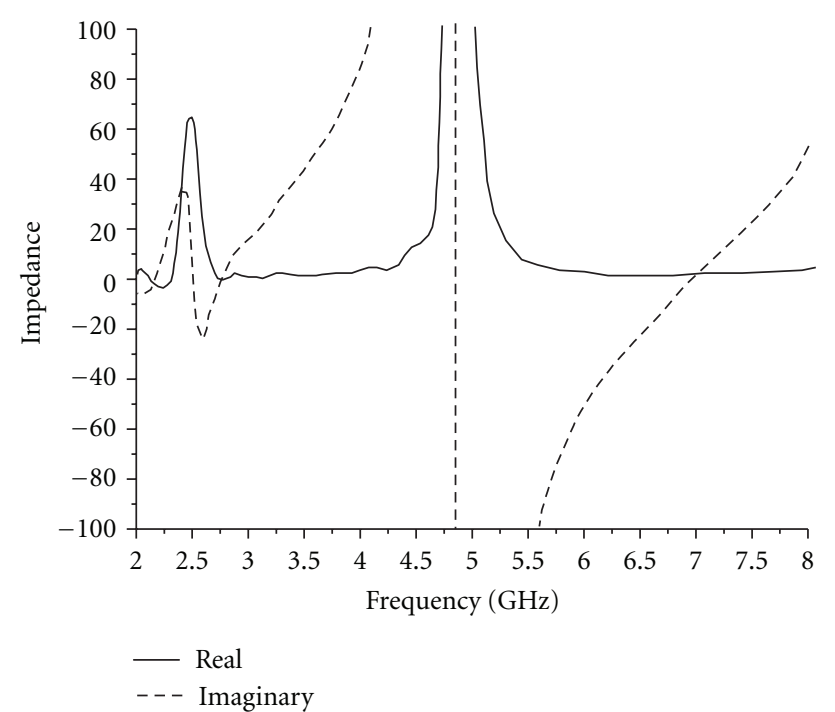

(b)

FIGURE 4: (a) The simulated return losses of antenna 2 and (b) The simulated input impedance of antenna 2. 


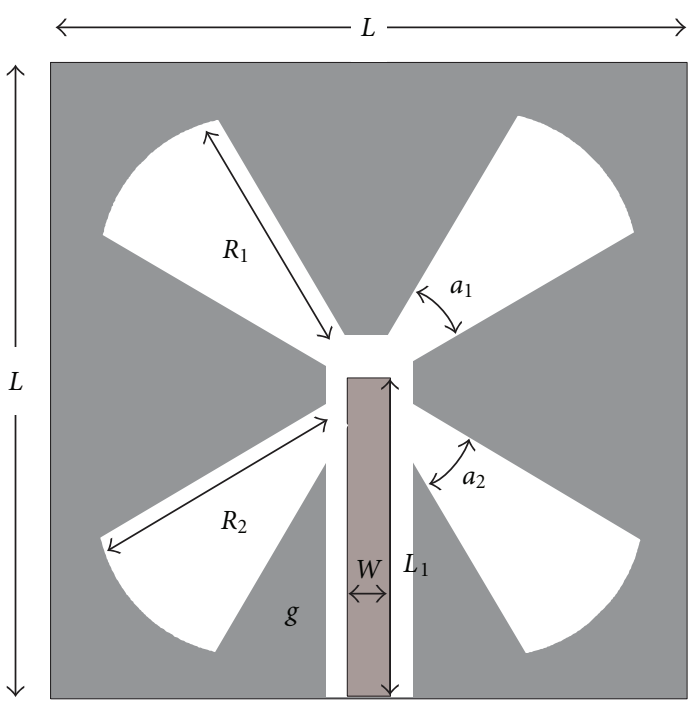

(a)

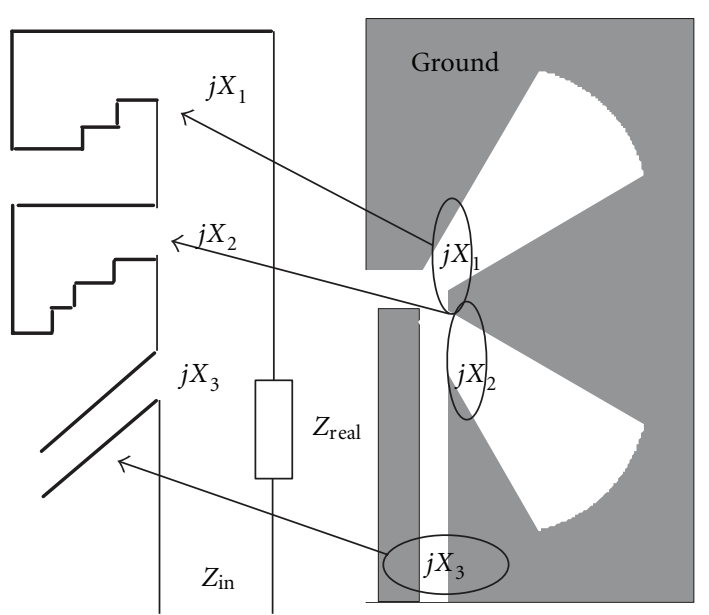

(b)

Figure 5: (a) The geometry of antenna 3 and (b) The equivalent transmission line circuits for antenna 3.

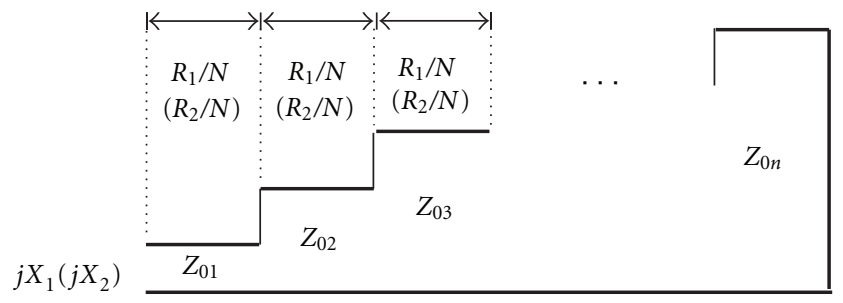

FIGURE 6: The equivalent transmission line model of the two pairs of symmetrical slots.

two desired fundamental frequencies. Thus, both harmonic suppression and wide bandwidth can be achieved when the two fundamental frequencies are close enough. The final optimized parameters are listed in Table 1, and Figure 7 demonstrates the final results.

\subsection{General Approach of Constructing Capacitive CPW-Fed} Slot-Type HSA. General approach of constructing capacitive CPW-fed slot type HSA can be summarized from what have mentioned above. Briefly, the design procedures are as follows:

(1) etching symmetrical slots connected with the end of the CPW-fed transmission line in the ground plane,

(2) calculate the slot length according to the equivalent transmission line circuits, and try to make the pure resistive input impedance obtained only at the desired fundamental resonant frequency,

(3) carefully adjust the parameters until optimized results are achieved,

(4) if wideband is required, extra slots can be connected with the end of the CPW transmission line,
(5) repeat step 1 to make sure the pure resistive input impedance only achieved at the desired resonant frequency, and it is close enough to the earlier one,

(6) carefully adjust the parameters until best results are obtained.

\section{Results and Discussion}

In order to verify the validation of the proposed antennas, experiments were carried out, and the measured results are plotted in Figures $8(\mathrm{a})$ and $8(\mathrm{~b})$, respectively. The measured $-10 \mathrm{~dB}$ impedance bandwidth of the proposed simple compact HSA (antenna 2) is $90 \mathrm{MHz}(2.4-2.49 \mathrm{GHz}$, $3.6 \%$ ) with compact size of $36 \mathrm{~mm} \times 24 \mathrm{~mm}$. The proposed compact broadband HSA (antenna 3) achieved a wide $-10 \mathrm{~dB}$ impedance bandwidth $(530 \mathrm{MHz})$ spanning from $2.25 \mathrm{GHz}$ to $2.78 \mathrm{GHz}$, which is about $150 \%$ broader than that proposed in [13]. Furthermore, the proposed compact broadband HSA (antenna 3 ) also exhibits compact size of $40 \mathrm{~mm} \times 40 \mathrm{~mm}$, which is about $47 \%$ smaller in size compared with the above-mentioned broadband HSA in [12].

The radiation patterns at different frequencies (at $2.45 \mathrm{GHz}, 4.9 \mathrm{GHz}$ and $7.35 \mathrm{GHz}$ ) for antenna 1 , antenna 2 


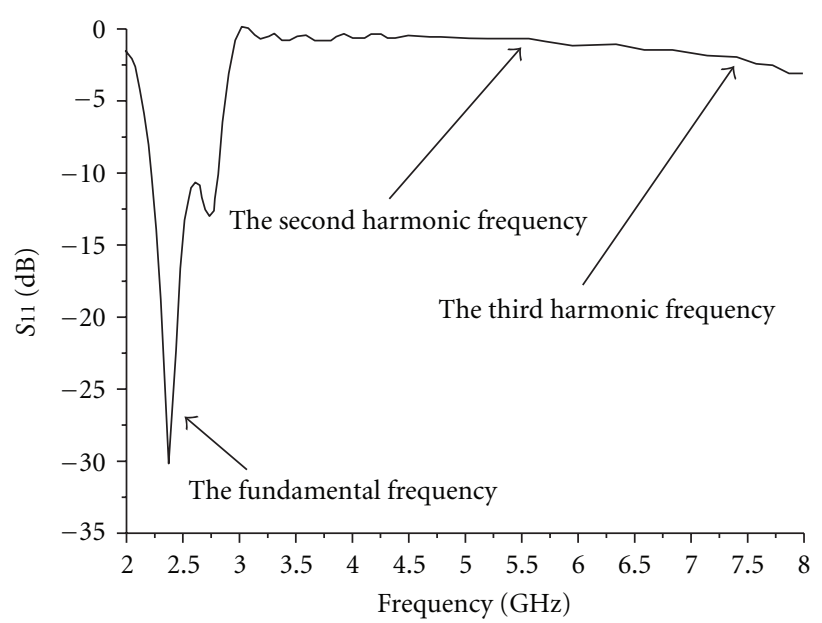

(a)

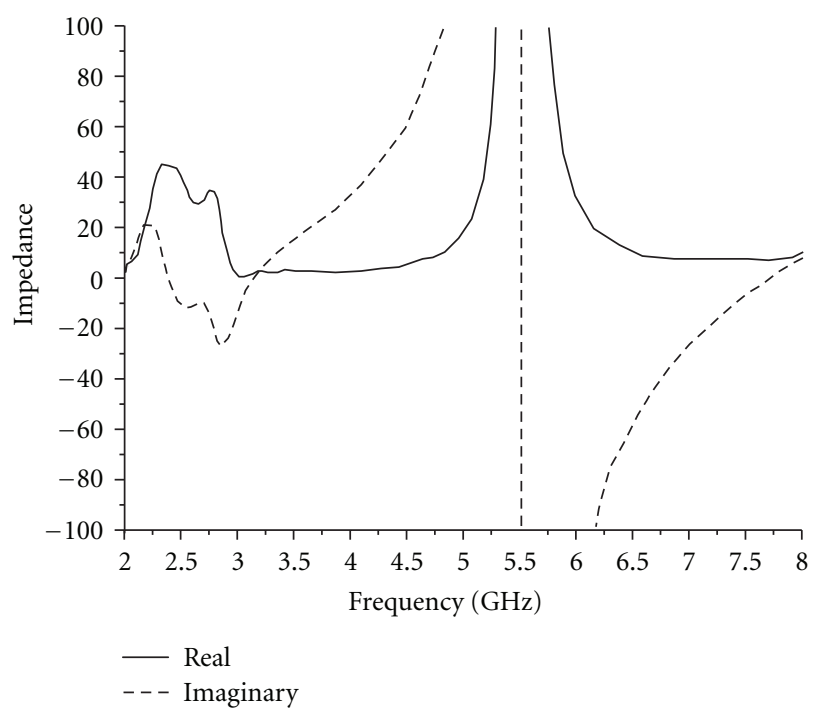

(b)

Figure 7: (a) The simulated return losses of antenna 3 and (b) The simulated input impedance of antenna 3.

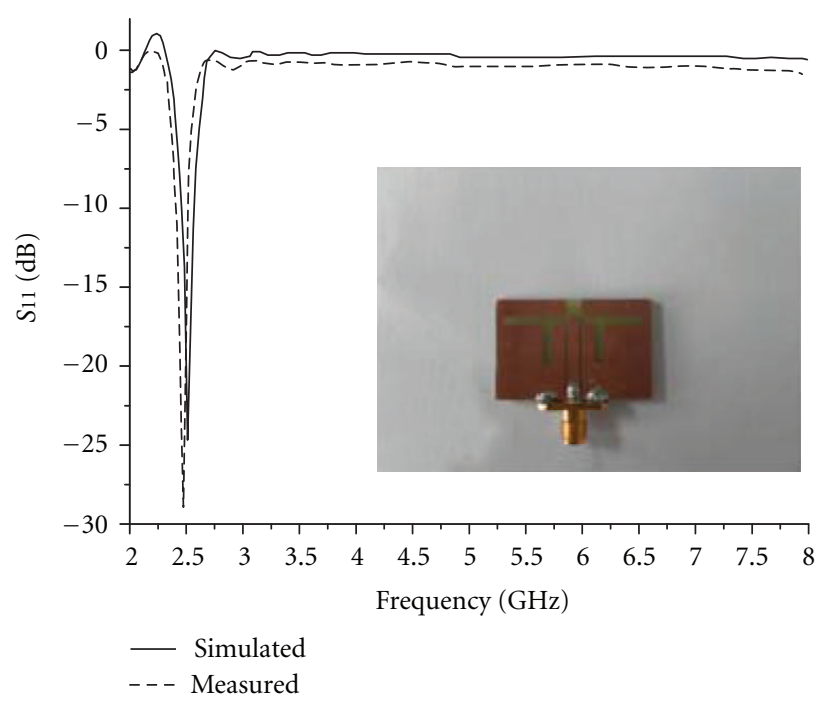

(a)

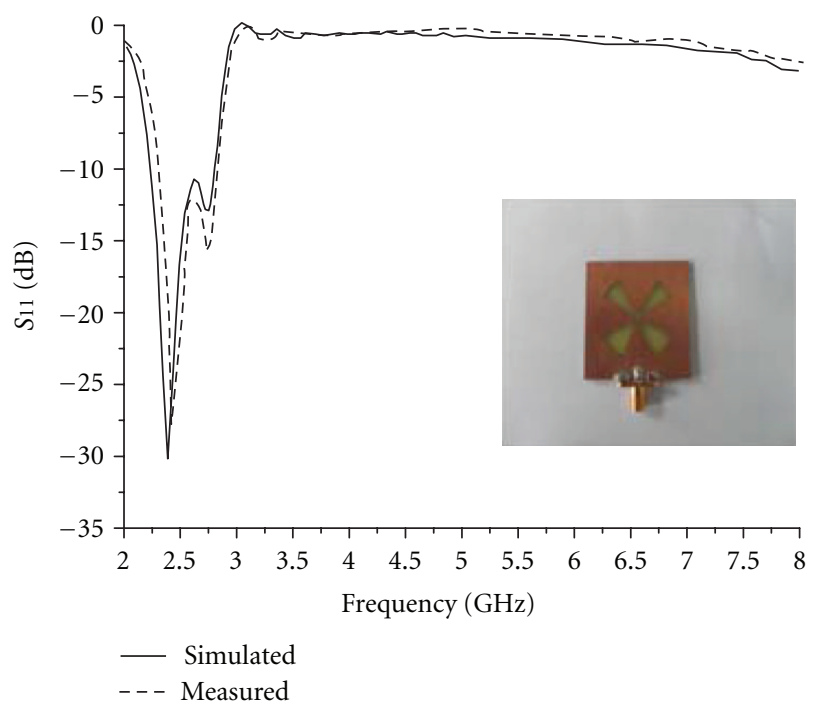

(b)

FIGURE 8: The simulated and measured return losses for (a) antenna 2 and (b) antenna 3.

and antenna 3 are also demonstrated in Figures 9(a), 9(b), and 9 (c), respectively. It can be seen that antenna 1 can only suppress the second harmonic frequency, while both antenna 2 and antenna 3 can suppress the second and third harmonic frequencies well.

\section{Conclusion}

In this paper, CPW-fed antennas with harmonic suppression including the second and third harmonic frequencies are demonstrated and investigated. By etching symmetrical slots connected to the end of the CPW-fed transmission line in the ground plane, and exploiting parasitic technology, both compact size and wide bandwidth are achieved. The proposed antenna has been verified through the equivalent circuit analysis and experimental results. General construction approach of such kind of HSA has also been derived. Given the merits such as compact size, good harmonic suppression, as well as wide bandwidth, the proposed HSA is very attractive for wireless communication and microwave power transmission applications.

\section{Acknowledgments}

This work was supported by the National Natural Science Foundation of China (nos. 61172115 and 60872029), 


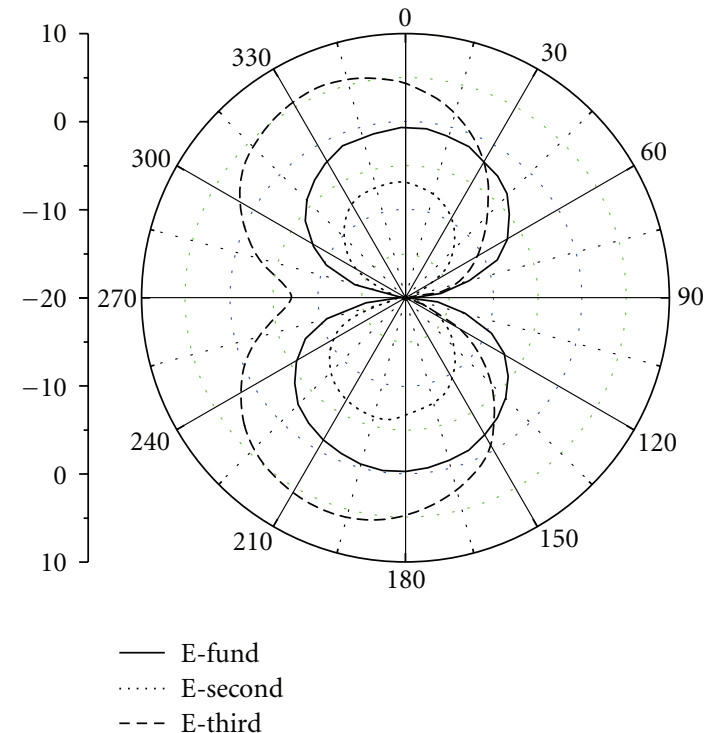

(a)

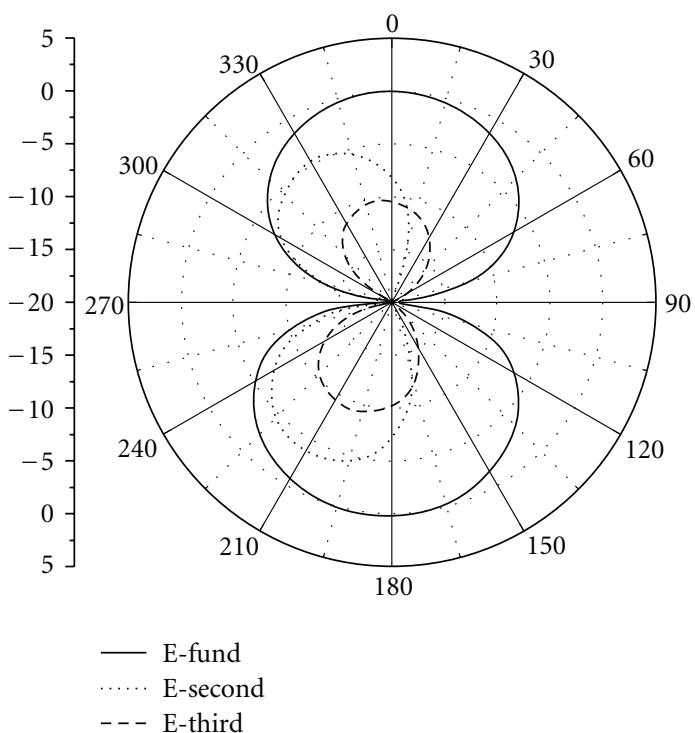

(b)

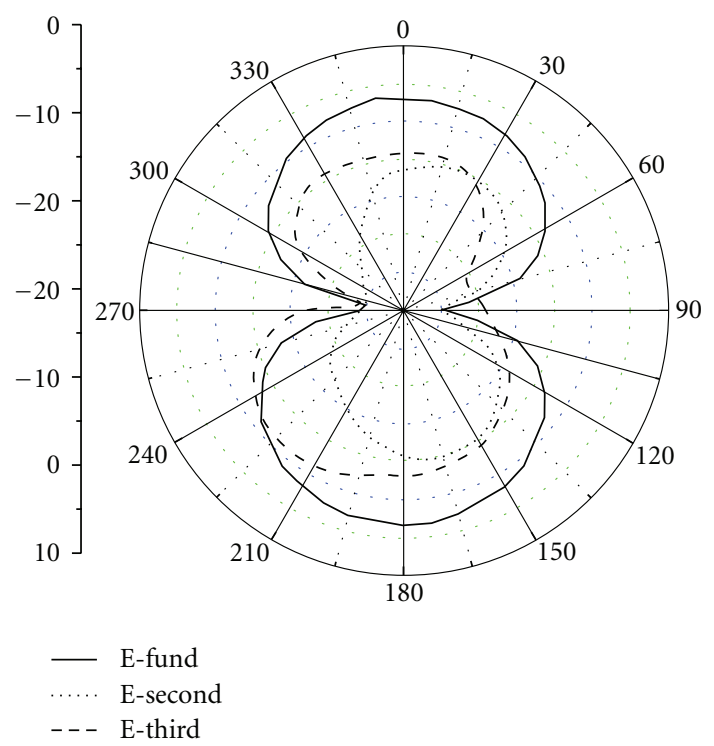

(c)

Figure 9: The radiation patterns at different frequencies for: (a) antenna 1, (b) antenna 2, and (c) antenna 3.

the High-Tech Research and Development Program of China (no. 2008AA01Z206), the Aeronautics Foundation of China (no. 20100180003), and the Fundamental Research Funds for the Central Universities (no. ZYGX 2009J037).

\section{References}

[1] V. Radisic, Y. Qian, and T. Itoh, "Novel architectures for high-efficiency amplifiers for wireless applications," IEEE Transactions on Microwave Theory and Techniques, vol. 46, no. 11, pp. 1901-1909, 1998.

[2] R. Dehbashi, Z. Atlasbaf, and K. Forooraghi, "New compact size microstrip antennas with harmonic rejection," IEEE Antennas and Wireless Propagation Letters, vol. 5, no. 1, pp. 395398, 2006.
[3] H. Kim and Y. J. Yoon, "Microstrip-fed slot antennas with suppressed harmonics," IEEE Transactions on Antennas and Propagation, vol. 53, no. 9, pp. 2809-2817, 2005.

[4] D. H. Choi, Y. J. Cho, and S. O. Park, "A broadband T-shaped microstrip-line-fed slot antenna with harmonic suppression," in Proceedings of the Asia-Pacific Microwave Conference (APMC'05), vol. 4, December 2005.

[5] Y. Horii, "A harmonically controlled microstrip patch antenna using grounded-pads embedded in an antenna substrate," in Proceedings of the IEEE International Antennas and Propagation Symposium and USNC/CNC/URSI North American Radio Science Meeting, pp. 724-727, June 2003.

[6] S. Kwon, B. M. Lee, Y. J. Yoon, W. Y. Song, and J. G. Yook, "A harmonic suppression antenna for an active integrated antenna," IEEE Microwave and Wireless Components Letters, vol. 13, no. 2, pp. 54-56, 2003. 
[7] J. Ding, "A harmonic suppression antenna using split ring resonators coupled with microstrip line," in Proceedings of the 7th International Symposium on Antennas, Propagation and EM Theory (ISAPE'06), pp. 1-3, October 2006.

[8] J. Y. Park, S. M. Han, and T. Itoh, "A rectenna design with harmonic-rejecting circular-sector antenna," IEEE Antennas and Wireless Propagation Letters, vol. 3, no. 1, pp. 52-54, 2004.

[9] J. Y. Park, S. M. Han, and T. Itoh, "Antenna with harmonic rejecting circular sector antenna," IEEE Antennas and Wireless Propagation Letters, vol. 5, pp. 395-398, 2006.

[10] I. Chang and B. Lee, "Design of defected ground structures for harmonic control of active microstrip antenna," in Proceedings of the IEEE Antennas and Propagation Society International Symposium, pp. 852-855, June 2002.

[11] H. Liu, Z. Li, X. Sun, and J. Mao, "Harmonic suppression with photonic bandgap And defected ground structure for a microstrip patch antenna," IEEE Microwave and Wireless Components Letters, vol. 15, no. 2, pp. 55-56, 2005.

[12] X. C. Lin and L. T. Wang, "A broadband CPW-fed loop slot antenna with harmonic control," IEEE Antennas and Wireless Propagation Letters, vol. 2, pp. 323-325, 2003.

[13] R. Sujith, S. Mridula, P. Binu, D. Laila, R. Dinesh, and P. Mohanan, "Compact CPW-fed ground defected H-shaped slot antenna with harmonic suppression and stable radiation characteristics," Electronics Letters, vol. 46, no. 12, pp. 812-814, 2010.

[14] W. H. Tu, "Compact harmonic-suppressed coplanar waveguide-fed inductively coupled slot antenna," IEEE Antennas and Wireless Propagation Letters, vol. 7, pp. 535-545, 2008.

[15] N. A. Nguyen, R. Ahmad, Y. T. Im, Y. S. Shin, and S. O. Park, "A T-shaped wide-slot harmonic suppression antenna," IEEE Antennas and Wireless Propagation Letters, vol. 6, pp. 647-650, 2007. 

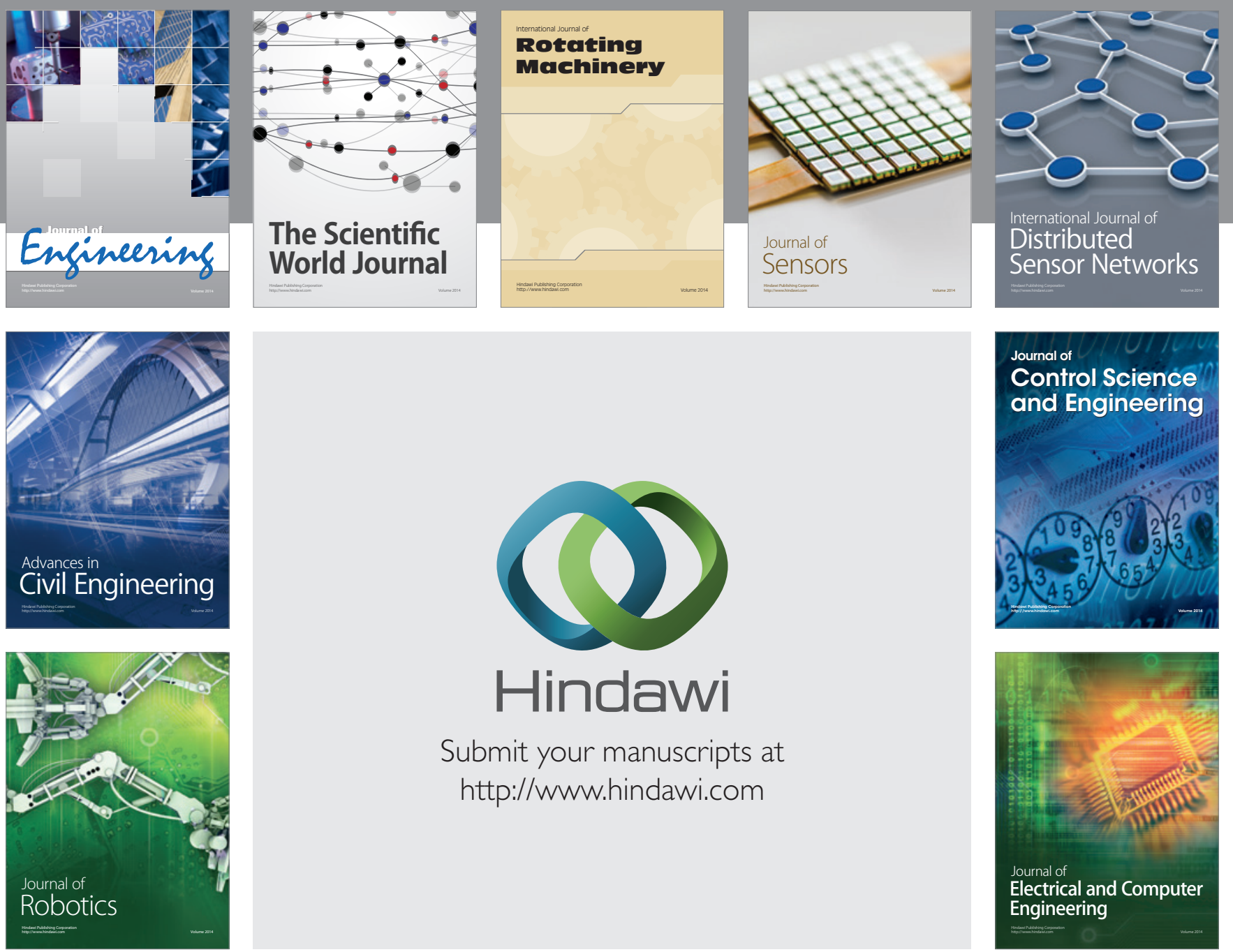

Submit your manuscripts at

http://www.hindawi.com
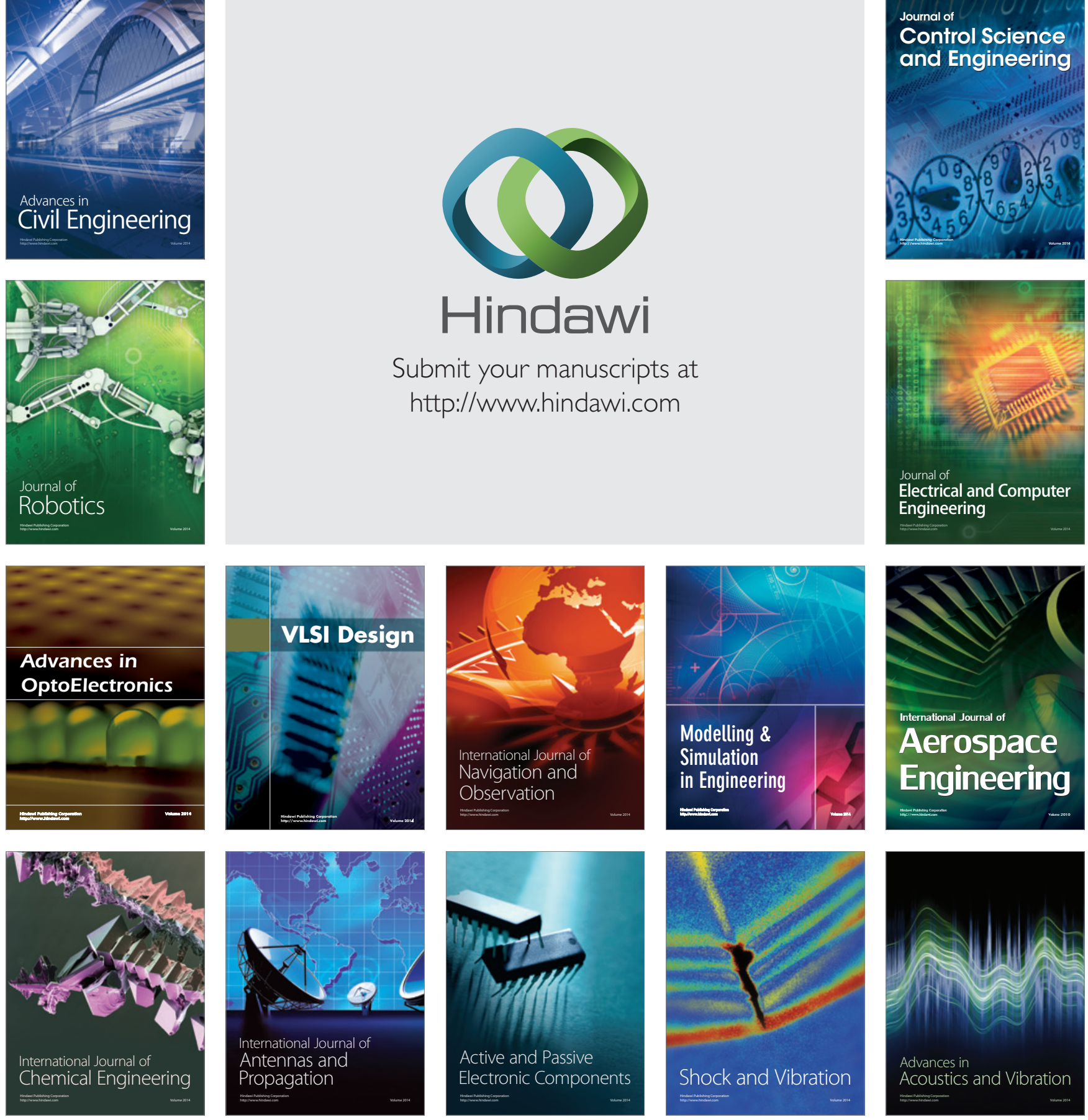